\title{
21. Formation of Boron-mannitol Complex in the Hydrofluoric Acid Solution and a Possibility of the Use of Acids in the Separation of Boron from the Natural Rock Samples
}

\author{
By Tsuyoshi Ishikawa and Eizo NaKamura \\ Institute for Study of the Earth's Interior, Okayama University, \\ Misasa, Tottori, 682-02 \\ (Communicated by Syun-iti Aкгмото, м. J. A., May 14, 1990)
}

\begin{abstract}
Volatilization and mass fractionation of boron during evaporation of the hydrofluoric and hydrochloric acid solutions were investigated with varying mannitol/boron ratios. The degree of volatilization and mass fractionation decreases with increasing mannitol/boron mol ratio and the boron volatilization is completely suppressed when the ratio is more than unity. These results indicate that the final stable compound of boron-mannitol complex is an equimolar complex of boron and mannitol. The formation of this complex allows the use of hydrofluoric and hydrochloric acids for the dissolution of silicate rock samples and for separation of boron from the samples adopting anion exchange chromatography in $\mathrm{F}^{-}$form.
\end{abstract}

Key words: Boron-mannitol complex; boron isotopic composition; mass fractionation.

Introduction. The content and isotopic abundance of boron in meteoritic and terrestrial materials are important in understanding of nuclear synthesis theories and geological phenomena, because of the high cross-section of boron isotope ${ }^{10} \mathrm{~B}$ for the thermal neutrons and of being strongly partitioned into liquid phase relative to mafic silicate minerals in the magmatic processes. However, only little data of boron isotopic composition are available to terrestrial and meteoritic samples due to difficulty of its separation and isotopic measurement.

Rock sample is usually digested and desired elements are chromatographically separated using acids, such as $\mathrm{HF}, \mathrm{HClO}_{4}, \mathrm{HCl}$ and $\mathrm{HNO}_{3}$. However, boron in the acidic solutions is easily volatilized during evaporation to dryness relative to neutral or alkaline solutions. This property of boron prohibits the use of acids in the separation of boron from natural rock samples. It is widely known that boric acid reacts with many hydroxy compounds such as alcohol or phenol to form stable complexes. In particular, mannitol is commonly adopted to the quantitative determination of boron,1),2) because it forms mannitoloboric acid complex by the reaction with boric acid and drastically raises the degree of electrolytic dissociation. Furthermore, some previous studies have revealed that mannitol suppressed the volatilization of boron from solutions of water, hydrochloric acid and nitric acid during evaporation.3),4) However, the volatilization of boron and resulting isotopic fractionation have not been examined for boronmannitol complex in the hydrofluoric acid and concentrated hydrochloric acid with the small amount of boron.

Reagents. Water deionized by mixed ion-exchange resin was subboiled using a pure quartz subboiling stills) and subsequently subboiled by a two-bottle Teflon still.6) Hydrofluoric acid and hydrochloric acid were subboiled using the 
two-bottle Teflon still and then the distillates were diluted to appropriate concentrations with the twice distilled water. National Bureau of Standards standard reference material (NBS SRM) 951 boric acid was used as a standard for the boron isotopic measurements. NBS SRM 952, boric acid enriched in ${ }^{10} \mathrm{~B}$ was employed as a spike for the isotope dilution analysis. These boric acids were dissolved in the twice distilled water to obtain $6.0013 \mathrm{ppm}$ and $4.08 \mathrm{ppm}$ boron concentrations for SRM 951 and 952, respectively. Analytical grade mannitol was liquefied in the water to give a $1000 \mathrm{ppm}\left(5.49 \times 10^{-3} \mathrm{M}\right)$ solution. Cesium carbonate was dissolved in the water to give a $9.25 \times 10^{-3} \mathrm{M}$ cesium solution. Spectroscopic grade graphite was mixed with an $50 \%$ ethanol/50\% water (v/v) solution to give a $40 \mathrm{mg} / \mathrm{mL}$ graphite.

Mass spectrometry. The thermal ionization mass spectrometer, MAT 261, was employed for the measurements of boron isotopic composition using the dicesium metaborate cation, $\left.\left.{ }^{\tau}\right)-9\right) \quad \mathrm{Cs}_{2} \mathrm{BO}_{2}^{+}$emitted from the stable compound of $\mathrm{Cs}_{2} \mathrm{~B}_{4} \mathrm{O}_{7}$. Cesium solution was added to the sample containing boron and mannitol to produce a $\mathrm{B} / \mathrm{Cs}$ mol ratio of 2 and then loaded onto the $\mathrm{V}$-shaped tantalum filament previously coated by $30 \mu \mathrm{g}$ graphite. After drying up under the heating lamp, the sample was introduced into the mass spectrometer. The ratio between $\mathrm{Cs}_{2}{ }^{10} \mathrm{BO}+(308 \mathrm{~m} / \mathrm{e})$ and $\mathrm{Cs}_{2}{ }^{11} \mathrm{BO}_{2}^{+}(309 \mathrm{~m} / \mathrm{e})$ was measured against the base line at $306.5(\mathrm{~m} / \mathrm{e})$. The ion current of $\mathrm{Cs}_{2}{ }^{11} \mathrm{BO}_{2}^{+}$was typically $1 \times 10^{-11} \mathrm{~A}$. Measured ratios were corrected for oxygen isotopes to exclude the interference of $\mathrm{Cs}_{2}{ }^{10} \mathrm{~B}^{16} \mathrm{O}^{17} \mathrm{O}^{+}$as follows: ${ }^{11} \mathrm{~B} /{ }^{10} \mathrm{~B}=$ (measured $309 / 308$ ratio) $-0.00079 .{ }^{8}$ )

Boron volatilization from the acid solutions in the presence of mannitol. In order to confirm whether or not mannitol suppresses the volatilization of boron from the hydrofluoric and hydrochloric acid solutions, recovery yields of boron during the evaporation to dryness were examined by varying the amount of mannitol. $0.5 \mathrm{~mL}$ of SRM 951 boric acid solution containing about $3 \mu \mathrm{g}$ boron $\left(2.8 \times 10^{-7} \mathrm{~mol}\right)$ was transferred into a concave-bottom Teflon beaker and weighed precisely. Various amounts of mannitol solution were added by weighing into the beakers to satisfy the mannitol/boron mol ratios ranging from 0 to 3 . Afterwards, $2 \mathrm{~mL}$ each of $3 \mathrm{M} \mathrm{HF}, 46 \% \mathrm{HF}$ and $6 \mathrm{M} \mathrm{HCl}$ was added one by one to the prepared samples and the solutions were then evaporated to dryness at a temperature of not more than $70^{\circ} \mathrm{C}$. Heating was stopped immediately when the evaporation was completed. Subsequently, $2.0 \times 10^{-7}$ mol boron of SRM 952 spike solution exactly weighed was added to the residua. Appropriate amounts of cesium solution to give a $\mathrm{B} / \mathrm{Cs}$ mol ratio of 2 and $50 \mu \mathrm{L}$ of mannitol solution $\left(2.2 \times 10^{-7} \mathrm{~mol}\right)$ were added to the spiked samples and then the solutions were again evaporated to dryness. The recovery yields of boron in the first evaporation were calculated from the given ${ }^{11} \mathrm{~B} /{ }^{10} \mathrm{~B}$ ratios by the isotope dilution method.

The results for $3 \mathrm{M} \mathrm{HF}$ solution are plotted in Fig. 1. The recovery yield from the mannitol-free $3 \mathrm{M} \mathrm{HF}$ solution is only $9 \%$. However, it drastically rises with increasing amounts of added mannitol, and reaches to about $90 \%$ when the mannitol/boron mol ratio is 0.5 . Complete recovery is achieved when the mannitol/boron mol ratio is more than unity. Similar results were also obtained for the $46 \% \mathrm{HF}$ and $6 \mathrm{M} \mathrm{HCl}$ solutions.

The recovery yield of boron implies the magnitude of formation of boronmannitol complex in hydrofluoric acid. Achievement of the complete boron recovery at the mannitol/boron mol ratio of 1 suggests that the final stable compound is an equimolar complex of boron and mannitol; i.e.[BL] where $\mathrm{B}$ and $\mathrm{L}$ are boron and mannitol, respectively. Nevertheless, the non linear and steeper 


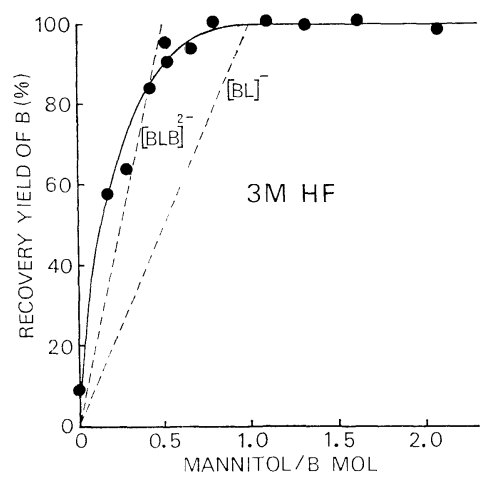

Fig. 1. Boron recovery yield after evaporation from $3 \mathrm{M} H F$ solution with varying mannitol abundance. Analytical errors are smaller than the symbol. Broken lines with $[\mathrm{BL}]^{-}$and $[\mathrm{BLB}]^{2-}$ represent the theoretical recovery lines expected when only $[\mathrm{BL}]^{-}$ and $[\mathrm{BLB}]^{2-}$ type complexes are independently formed, respectively.

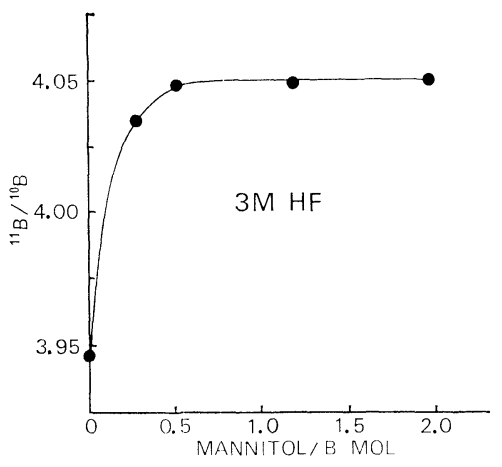

Fig. 2. Boron isotopic compositions of the evaporation residua from the $3 \mathrm{M} \mathrm{HF}$ with changing mannitol/boron mol ratio. Analytical errors are smaller than the symbol.

gradient of the boron recovery curve in the range of mannitol/boron ratio $<0.5$ strongly suggests the formation of $[\mathrm{BLB}]^{2-}$-form complex in addition to $[\mathrm{BL}]^{-}$ complex. In the $[\mathrm{BLB}]^{2-}$ complex, two pairs of cis-OH sites in mannitol are both occupied by boron. The two broken lines in Fig. 1 indicate the theoretical recoveries of boron resulted from the formation of $[\mathrm{BLB}]^{2-}$ and $[\mathrm{BL}]^{-}$type complexes, respectively. From the above observations, the following aspects can be pointed out in terms of the structure of boron-mannitol complex: (1) When mannitol/boron ratio is smaller than 0.5 , the dominant form of boron-mannitol complex is $[\mathrm{BLB}]^{2-}$. (2) With increasing the ratio, the $[\mathrm{BLB}]^{2-}$ complex is progressively replaced by $[\mathrm{BL}]^{-}$complex and/or more polymerized form, $[\mathrm{BL}]_{\mathrm{n}}^{\mathrm{n}-}$. (3) When the ratio is more than 1 , all boron occurs as [BL]--type complex. The presence of $[\mathrm{LBL}]^{-}$complex in aqueous solution ${ }^{10}$ ) is not consistent with our 
results. This disagreement, however, might be originated from the difference in boron species existing in aqueous solution and hydrofluoric acid solution. In the hydrofluoric acid solution, boron occurs entirely as $\mathrm{BF}_{4}^{-}$, whereas in aqueous solution, boron exists as $\mathrm{B}(\mathrm{OH})_{3}, \mathrm{~B}(\mathrm{OH})_{4}^{-}$or other polyborates.

Examination of isotopic fractionation. Isotopic compositions of residual beron after the evaporation of acid solutions were measured to investigate the isotopic fractionation resulted from the volatilization of boron. SRM 951 solution was taken into individual Teflon beakers to provide $3 \mu \mathrm{g}$ boron $\left(2.8 \times 10^{-7} \mathrm{~mol}\right)$ with various amounts of mannitol up to $100 \mu \mathrm{g}$ ( $550 \mathrm{nmol}) .2 \mathrm{~mL}$ of $3 \mathrm{M} \mathrm{HF}$ was added to the beakers as well as $2 \mathrm{~mL}$ of $46 \% \mathrm{HF}$ and $6 \mathrm{M} \mathrm{HCl}$. The evaporation of solutions was subsequently carried out in a similar way to the former experiment. Boron isotopic compositions of the remainders were then determined.

The obtained isotope ratios are plotted against mannitol/boron mol ratio in $3 \mathrm{M} \mathrm{HF}$ on Fig. 2. Without mannitol, residual boron shows an extremely low ${ }^{11} \mathrm{~B} /{ }^{10} \mathrm{~B}$ ratio indicating the preferential enrichment of ${ }^{11} \mathrm{~B}$ into the gas phase in the form of $\mathrm{BF}_{3}$ or $\mathrm{BCl}_{3}$ during the evaporation of solution. Fig. 2 indicates that the ${ }^{11} \mathrm{~B} /{ }^{10} \mathrm{~B}$ ratio of the residue increases with increasing the amount of mannitol relative to boron and becomes constant at mannitol/boron mol ratios of more than 1 as predicted in Fig. 1. Constant boron isotopic compositions were obtained for the residua satisfying mannitol/boron mol ratio $>1$ within the experimental errors regardless of acid concentration. These isotopic ratios firmly agree with the previously reported ${ }^{11} \mathrm{~B} /{ }^{10} \mathrm{~B}$ value $(4.05037 \pm 0.00022)$ for SRM 951, ${ }^{9)}$ which was determined by $\mathrm{Cs}_{2} \mathrm{BO} \mathrm{O}_{2}^{+}$method without any use of strong acid.

Application to the boron isotopic analysis in natural samples. In the course of boron isotope analysis on natural samples, any chemical operation accompanied by acid treatment has previously been restricted due to the boron isotopic fractionation during evaporation of the solution. Thus sample decomposition and subsequent chemical procedures have been carried out usually in the presence of excess alkali. The most general method for separation of boron from natural rock samples for that purpose is a methyl borate distillation technique after decomposition of sample with alkali fusion.e.g.11),12) In that method, it is difficult to achieve the high recovery yield of boron so that a considerably larger isotopic fractionation arises during the distillation.13) Furthermore, alkali fusion requires a large amount of flux such as sodium carbonate and high temperature exceeding $800^{\circ} \mathrm{C}$. This sample decomposition method might, therefore, magnify boron blank and discharge boron from the sample in crucible.

As revealed above, mass fractionation and volatilization of boron during evaporation of the hydrofluoric and hydrochloric acid solutions are completely suppressed when mannitol/boron mol ratio is more than unity. This property of mannitol with boron enables us to make use of hydrofluoric and hydrochloric acids in the course of boron separation from the natural samples, especially form silicate rock samples for the isotopic analysis. Sample decomposition can be performed with concentrated hydrofluoric acid generally employed in isotopic analysis such as for $\mathrm{Sr}$ and $\mathrm{Nd}$. Since boron behaves as $\mathrm{BF}_{4}^{-}$in the hydrofluoric acid solution, it is possible to isolate boron from other elements in the natural rock and solution samples adopting anion exchange chromatography in $\mathrm{F}^{-}$form. Most of the major elements of rock samples in the hydrofluoric acid solution are not adsorbed in the anion exchange resin because they behave as cations. Therefore, a large ion-exchange capacity is not required in this method for boron separation. This makes it possible to reduce the volume of resin and eluent, and 
consequently diminish the total blank in the course of boron separation. Consequently, it is conceivable to separate trace amounts of boron from natural rock samples such as basalts, ultramafic xenoliths and meteorites which have extremely low boron concentrations $(<1 \mathrm{ppm})$. We have actually developed a new technique to determine the precise isotopic composition of trace amount of boron $(<0.5 \mu \mathrm{g})$ in natural samples such as volcanic rocks from Japanese island arcs, using anion exchange chromatography with mannitol, which will be described in detail elsewhere. ${ }^{14)}$

Acknowledgments. We thank M. Kusakabe and E. S. Beary for comments and criticism regarding this work and for providing the spectroscopic grade graphite, respectively. We are deeply indebted to Prof. S. Akimoto, M. J. A., for his encouragement.

\section{References}

1) Povondra, P., and Hejl, V. (1976) : Collect. Czech. Chem. Commun., 41, 1343-1347.

2) Pelletier, E., and Lebel, J. (1977) : Can. J. Earth Sci., 15, 618-625.

3) Feldman, C. (1961): Anal. Chem., 33, 1916-1920.

4) Kuwada, K. et al. (1978): ibid., 50, 1788-1792.

5) Kuehner, E. C. et al. (1972) : ibid., 44, 2050-2056.

6) Mattinson, J. M. (1972) : ibid., 44, 1715-1716.

7) Ramakumar, K. L. et al. (1985) : J. Radioanal. Nucl. Chem., 94, 53-62.

8) Spivack, A. J., and Edmond, J. M. (1986): Anal. Chem., 58, 31-35.

9) Xiao, Y. K. et al. (1988): Int. J. Mass Spectrom. Ion Processes, 85, 203-213.

10) Barbier, Y., and Rosset, R. (1968): Bull. Soc. Chim. Fr., 12, 5072-5077.

11) Shima, M. (1962) : J. Geophy. Res., 67, 4521-4523.

12) Agyei, E. K., and McMullen, C. C. (1968): Can. J. Earth Sci., 5, 921-927.

13) Kanzaki, T. et al. (1978): Bunseki Kagaku, 27, 481-485.

14) Nakamura, E. et al. (1990): (in preparation). 